\title{
Bioelectrochemical systems for energy storage: A scaled-up power-to-gas approach
}

\author{
Alba Ceballos-Escalera ${ }^{\mathrm{a}}$, Daniele Molognoni ${ }^{\mathrm{a}, *}$, Pau Bosch-Jimenez ${ }^{\mathrm{a}}$, Mahdi Shahparasti ${ }^{\mathrm{b}}$, \\ Salim Bouchakour ${ }^{\mathrm{b}}$, Alvaro Luna ${ }^{\mathrm{b}}$, Albert Guisasola ${ }^{\mathrm{c}}$, Eduard Borràs ${ }^{\mathrm{a}}$, Monica Della Pirriera ${ }^{\mathrm{a}}$ \\ ${ }^{a}$ LEITAT Technological Center, C/ de la Innovació 2, 08225 Terrassa, Spain \\ ${ }^{\mathrm{b}}$ Department of Electrical Engineering, Universitat Politècnica de Catalunya, 08222 Terrassa, Spain \\ ${ }^{\mathrm{c}}$ Department of Biological, Environmental and Chemical Engineering, Universitat Autònoma de Barcelona, 08193 Bellaterra (Barcelona), Spain
}

\section{H I G H L I G H T S}

- Bioelectrochemical systems can be used as power-to-gas technology for energy storage.

- A BES prototype was long-term operated to store electric energy in the form of biomethane.

- The prototype produced $4.4 \mathrm{~L} \mathrm{CH}_{4} \mathrm{~m}^{-2} \mathrm{~d}^{-1}$ with an energy storage efficiency of $42-47 \%$.

- Electric behavior of BES prototype was simulated to design its electric converter.

- Future research increasing current density demand can lead to positive business case.

\section{A R T I C L E I N F O}

\section{Keywords:}

Biomethane

Electromethanogenesis

Microbial electrochemical technologies

Modelling

Power-to-gas

Renewable energy

\begin{abstract}
A B S T R A C T
The development and implementation of energy storage solutions is essential for the sustainability of renewable energy penetration in the electrical system. In this regard, power-to-gas technologies are useful for seasonal, high-capacity energy storage. Bioelectrochemical systems for electromethanogenesis (EMG-BES) represent an additional power-to-gas technology to the existing chemical and biological methanation. EMG-BES process can be retrofitted in traditional anaerobic digesters, with advantages in terms of biologic process stability and highquality biogas production. Nowadays, there are no reported studies of scaled-up EMG-BES plants for energy storage. The present work describes the setup and operation of a medium-scale EMG-BES prototype for power-togas, storing energy in the form of biomethane. The prototype was built by stacking 45 EMG-BES cells, accounting for a total volume of $32 \mathrm{~L}$. It was continuously fed with $10 \mathrm{~L} \mathrm{day}^{-1}$ municipal wastewater, and it was long-term operated at different voltage and temperature ranges. A steady-state current density demand of $0.5 \mathrm{~A} \mathrm{~m}^{-2}$ was achieved at $32{ }^{\circ} \mathrm{C}$ while producing $4.4 \mathrm{~L} \mathrm{CH}_{4} \mathrm{~m}^{-2} \mathrm{~d}^{-1}$ and removing $70 \%$ of the initial organic matter present in wastewater. Microbial competition between electro-active bacteria and acetoclastic methanogens was observed. Energy storage efficiency was estimated around 42-47\%, analyzing surplus $\mathrm{CH}_{4}$ production obtained when applying voltage to the stack. A first order electric model was calculated, based on the results of a series of electrical characterization tests. The model may be used in the future to design the converter for EMG-BES plant connection to the electrical grid. The obtained results show that energy storage based on EMG-BES technology is possible, as well as its future potential, mixing renewable power overproduction, biomethane generation and wastewater treatment under the circular economy umbrella.
\end{abstract}

\section{Introduction}

The European Commission set ambitious decarbonization and energy efficiency targets in an attempt to fight climate change, including the reduction of greenhouse gas emissions by $40 \%$ by 2030 and the increase of renewable energy share (RES) to at least $27 \%$ by 2030 [1]. Public and private entities are investing heavily in RES, with wind and solar being the predominant technologies, but these energy sources are intermittent by nature and subject to major seasonal variations. It is therefore becoming more difficult to match energy production and

\footnotetext{
* Corresponding author.

E-mail address: dmolognoni@leitat.org (D. Molognoni).
} 


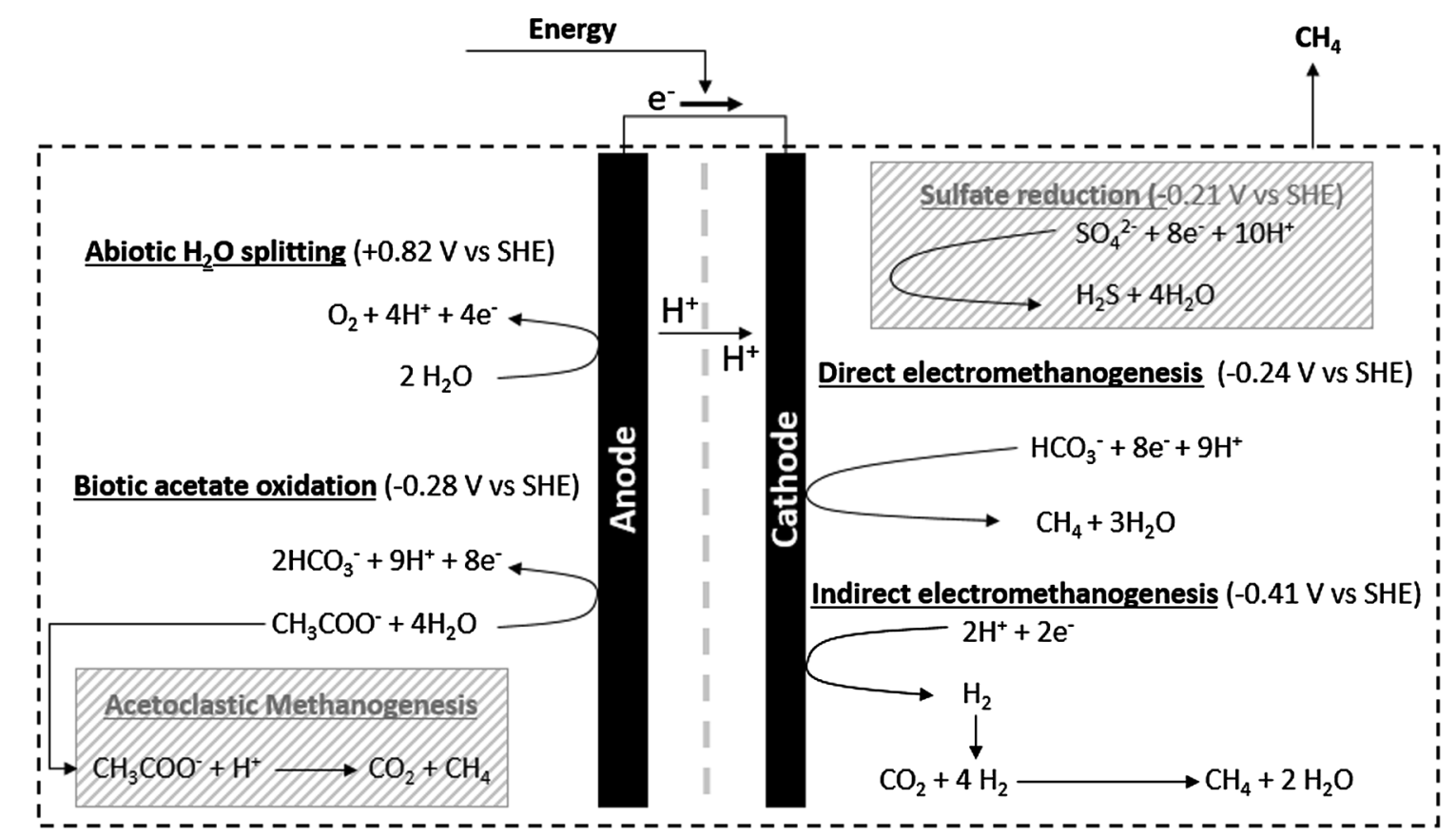

Fig. 1. Possible reactions taking place in an EMG-BES reactor. Acetate $\left(\mathrm{CH}_{3} \mathrm{COO}^{-}\right)$is used as a model of organic matter in the anode chamber.

demand. Electricity surpluses are becoming an issue for dedicated grid operators, with the potential to compromise the stability of the entire electric grid, and with associated economic losses [2]. In general, when installed RES power is higher than $30-40 \%$ of the overall energy mix [3], the problems of integrating this variable electricity supply into the distribution grid result in flexibility issues [4], finally impacting on the voltage and frequency stability. In order to overcome these issues, energy storage systems will play a decisive role in the future.

Energy storage can provide both upward and downward flexibility, storing energy either when there is generation surplus or lower demand, and discharging in the opposite case. Depending on the time scale (milliseconds up to months), storage technologies can play different roles [5]. At the present time, there are many solutions dealing with short-term energy storage, such as supercapacitors, batteries or flywheels. These technologies work well when it is necessary to deal with fast power changes and almost instantaneous energy delivery or absorption (from kWh to MWh scale) [2]. In addition, they can be scaled up rapidly but still they cannot deal with the need of achieving large-scale storage (TWh scale), as it is not either technically or economically feasible. On the other hand, pumped hydro or compressed air storage are good candidates for large-scale storage, but they require large investments and construction efforts. These technologies accomplish with the mismatch between energy production and demand over long periods (seasons). This is of great interest, as flexibility markets are being developed and a high amount of large-scale dispatchable storage will be necessary [6].

Conventional power-to-gas (P2G) technology is an alternative that can help converting high amounts of surplus electric energy from RES into more easily storable gas fuels [7]. This technology, based on the Sabatier process, relies on water electrolysis to obtain $\mathrm{H}_{2}$. This $\mathrm{H}_{2}$ can be used in a second reaction step to convert $\mathrm{CO}_{2}$ (pure or from biogas) to synthetic natural gas (SNG), containing $\mathrm{CH}_{4}$ as a major component [8]. According to EU regulations [9], SNG can be injected into the natural gas grid (unlike $\mathrm{H}_{2}$ ) or can be directly used as vehicle fuel [10]. Therefore, P2G technology permits the interconnection between the electric and natural gas distribution grids, reducing the overall energy cost while improving system resiliency and security [11]. The technology can handle fast power changes, although its potential is especially interesting for handling large amount of kWh for several hours, with a relative low investment that takes advantage of the existing gas infrastructure. Currently, there are two methods to obtain $\mathrm{CH}_{4}$ by P2G under development and with industrially reliable production capacity: the chemical and biological methanation.

The P2G by chemical methanation is based on the use of a chemical catalyst (e.g. nickel-based catalysts) and is characterized by high reaction rate and efficiency [12]. However, it is limited by high temperature $\left(150-800^{\circ} \mathrm{C}\right)$ and pressure $(8-30$ bar) requirements [13]. Several projects applied this methanation process on pilot scale P2G plants. For example, the company HZI Etogas designed and operated the largest P2G industrial plant in the world (6 MW electric power) for Audi in 2013; this plant was able to produce $325 \mathrm{Nm}^{3} \mathrm{SNG} \mathrm{h}^{-1}$ with an energy efficiency of 54\% [14]. On the other hand, biological methanation relies on microorganisms (hydrogenotrophic methanogens) as catalyst to produce biomethane from $\mathrm{CO}_{2}$. The term biomethane defines a biogas rich in $\mathrm{CH}_{4}(>95 \% \mathrm{v} / \mathrm{v}$ ), obtained from a biological source, which can be injected into the gas grid or used as vehicle fuel $[15,16]$. Biological methanation has lower efficiency but also some advantages compared to chemical methanation, operating at lower temperature $\left(40-70{ }^{\circ} \mathrm{C}\right)$ and pressure (1-8 bar) [17]. Successful biological methanation performance has been reported at both pilot and industrial scale. For example, MicrobEnergy is operating since 2013 the first industrial P2G plant based in biological methanation, producing $5.4 \mathrm{Nm}^{3} \mathrm{SNG}$ $\mathrm{h}^{-1}$ at $75 \% \mathrm{CH}_{4}$ content [18]. Nevertheless, both methanation processes have on-site $\mathrm{H}_{2}$ requirements and its solubility in water (compared to $\mathrm{CO}_{2}$ ) represents a limiting step [12]. In addition, the dwell time in electrolysis and methanation steps has a direct impact on SNG production cost, due to the availability of storage capacity for $\mathrm{H}_{2}$ or $\mathrm{CO}_{2}$ [19].

Bioelectrochemical systems (BES) emerged as a novel alternative for P2G plants. BES use electro-active microorganisms as renewable catalysts for wastewater treatment, with the concomitant recovery of energy and/or resources [20]. Standard BES configuration comprises an anode, where organic matter is oxidized, and a cathode, where a counter reaction occurs (if needed, separated by an ionic exchange membrane) [21]. Cheng et al. [22] were the first to propose cathodic reduction of $\mathrm{CO}_{2}$ (dissolved into an aqueous medium) into $\mathrm{CH}_{4}$ by BES. The technology is based on microbial electromethanogenesis (EMG), where the cathode acts as electron donor for the biotic reduction 
reaction. This can be achieved by either the direct reduction of $\mathrm{CO}_{2}$ to $\mathrm{CH}_{4}$ (direct EMG) or via $\mathrm{H}_{2}$ as electron mediator (indirect EMG). It was demonstrated for direct EMG to be more efficient th an $\mathrm{H}_{2}$-mediated one, the former taking place at a higher reduction potential (Fig. 1) [23]. At the anode, electrons can be provided by water electrolysis (abiotic reaction) or organic matter oxidation by electro-active bacteria. Therefore, biomass waste is not strictly required as electron donor for biological methane production, contrarily to anaerobic digestion. However, from an energetic point of view, a bioanode performing oxidation of organic matter is more valuable, reducing the potential difference $\mathrm{w}$ ith $\mathrm{t}$ he $\mathrm{c}$ athode $\mathrm{c}$ ompared to $\mathrm{w}$ ater e lectrolysis, $\mathrm{i}$.e. the voltage that must applied to the electromethanogenic BES (hereafter, EMG-BES). From authors' experience, a voltage of $0.7-1.2 \mathrm{~V}$ is required to run the EMG-BES process at a significant rate. In the present work, a single-chamber EMG-BES reactor architecture was employed. Thus, wastewater treatment can be achieved at the anode side, while produced $\mathrm{CO}_{2}$ was reduced to $\mathrm{CH}_{4}$ at the cathode side.

This strategy can be retrofitted also in traditional anaerobic digesters by introducing a pair of electrodes in the reactor body, an application known as BES-improved anaerobic digestion [24-27]. In this case, EMG (mainly driven by cathode produced $\mathrm{H}_{2}$ ) adds up to acetoclastic methanogenesis as $\mathrm{CH}_{4}$ production mechanism, leading to advantages including: (i) higher biogas productivity and quality (in terms of $\mathrm{CH}_{4}$ content) [28]; (ii) improved process stability, as acetate oxidation at the anode can reduce acid regression phenomena [29]; and (iii) possibility to operate at lower temperatures than mesophilic range [30]. Parasitic reactions can also take place in BES-improved digesters, like sulphate reduction, producing $\mathrm{H}_{2} \mathrm{~S}$ which can affect process efficiency and contaminates biogas (Fig. 1).

Bioelectrochemical P2G has several potential advantages compared to the previously mentioned methanation technologies. Besides being a single step process (no separate reactor for water electrolysis to $\mathrm{H}_{2}$ ), it can occur at lower temperature and pressure $\left(25-35^{\circ} \mathrm{C}\right.$, atmospheric pressure) than the other two methanation alternatives, potentially reducing the operational costs without affecting t he $g$ enerated biomethane quality. Moreover, microbial catalytic activity is not lost over time, as it occurs for chemical processes. On the other hand, the EMGBES technology is not characterized by fast dynamics. So, its niche is not to deal with power peaks but to play a significant role in large-scale storage. This does not mean that the system would not be able to absorb power peaks (in fact it does), but it is not able to release this energy with the same dynamics. Power absorption capacity of the system represents an aspect to study more in detail, once higher power densities will be achieved in the future.

Despite the potential of EMG-BES technology, it is in its early stage of development (its technology readiness level is around 3-4). Obtained $\mathrm{CH}_{4}$ production rates and power densities are still low compared to other methanation technologies [17]. For these reasons, no scaled-up EMG-BES plants for P2G have been reported so far, to the best of the authors' knowledge, although they may prove the process efficiency in a relevant environment. Scaling-up from laboratory to pilot-scale plants in previous experiences (related to different BES applications) showed that the strategy should be based on a combination of stacking individual reactors and increase of reactor volume, maintaining geometric invariables like the ratio between electrode surface and reactor volume [31-33]. A stacked architecture may also facilitate plant operation, allowing to power the stack at a higher voltage than the single EMG-BES cell (in case of series connection), and/or to take out and replace the defective modules without switching off the entire plant.

In order to use EMG-BES as a P2G energy storage technology, an electric converter must be installed upstream the plant, connecting it to the electric grid [34]. This because grid voltage is AC, while required voltage for EMG-BES is a regulated DC voltage (Fig. 2). Depending on grid conditions and electricity price, the converter should have two operation modes:
(1) Standby mode: feeding current is kept around zero, and there is no power exchange between grid and EMG-BES stack. The converter goes to this mode when the frequency of the grid is below a certain nominal value or if the electricity price is high;

(2) Power mode: the converter applies a variable and regulated voltage to the stack to adjust the value of the exchanged power with the grid. The converter changes to this mode when the electricity price is low or under episodes of RES surpluses.

The electric behavior of the EMG-BES plant must be determined, both in steady state and transient conditions, to design the proper electric converter. This engineering aspect is rarely discussed in BES literature, even though is key for a successful industrialization of the technology in near future.

In terms of electric optimization, some approaches have been proposed for the real-time monitoring and operation of BES reactors $[35,36]$. In one study, $\mathrm{H}_{2}$ production of a microbial electrolysis cell (MEC) was maximized by conducting a real-time optimization of the applied voltage [37]. In a more recent study, an equivalent electric circuit model of MEC was developed to monitor in real-time its internal resistance and capacitance [38]. The model was then capable of tracking changes of the reactor operating conditions, including variations in the influent chemical oxygen demand (COD) [39]. However, no similar studies were proposed up to date in the field of EMG-BES for energy storage.

This multidisciplinary study describes the operation of a mediumscale EMG-BES prototype for $\mathrm{CH}_{4}$ production and electricity storage. A complete assessment in terms of wastewater treatment efficiency, $\mathrm{CH}_{4}$ production, current and power consumption was performed. The energy storage efficiency of the prototype was estimated, in order to evaluate the potential of the technology in view of a P2G approach. A series of electric characterization tests were finally performed to model the prototype electric behavior.

\section{Materials and methods}

\subsection{Design and construction of EMG-BES prototype}

A medium-scale EMG-BES prototype was designed and built by stacking 45 cells together, grouped by 3 into 15 single-chamber, membrane-less reactor modules (Fig. 3). The volume of each module was $1.78 \mathrm{~L}$ (plus $5.2 \mathrm{~L}$ due to recirculation tank and piping volumes), reaching a total volume of $32 \mathrm{~L}$. Anode and cathode electrodes $\left(170 \mathrm{~cm}^{2}\right.$ projected surface, each one) were made of thermally activated carbon felt (SGL group, Germany). The total cathode surface accounted for $0.77 \mathrm{~m}^{2}$. The electrical connection to the external circuit was made by stainless steel frames as current collectors. The complete stack of cells was electrically connected in parallel and powered at $0.7 \mathrm{~V}$ by a power source (TENMA 72-2715, Farnell, Spain). The value of applied voltage was based on previous laboratory experience.

In order to maintain homogeneous internal condition, the modules were connected hydraulically in parallel to a single recirculation tank (5 L volume, glass-made, jacketed), through 4 multi-channel pumps. These were recirculating wastewater at a rate of $50 \mathrm{~mL} \mathrm{~min}^{-1}$ per module. The recirculation tank was kept in mixing conditions by a stirring plate, and at a constant temperature by a heating system connected to the external jacket (Huber thermostat CC-K6, Huber, Germany). The gas produced by the prototype was trapped by 3 external chambers (each one connected to 5 modules). A process and instrumentation diagram (P\&ID) is available in Supplemental Information (SI), Fig. S1.

\subsection{Inoculation and operation strategies}

The prototype was inoculated in batch mode by a mixture of anaerobic sludge (collected from the anaerobic digester of Terrassa 


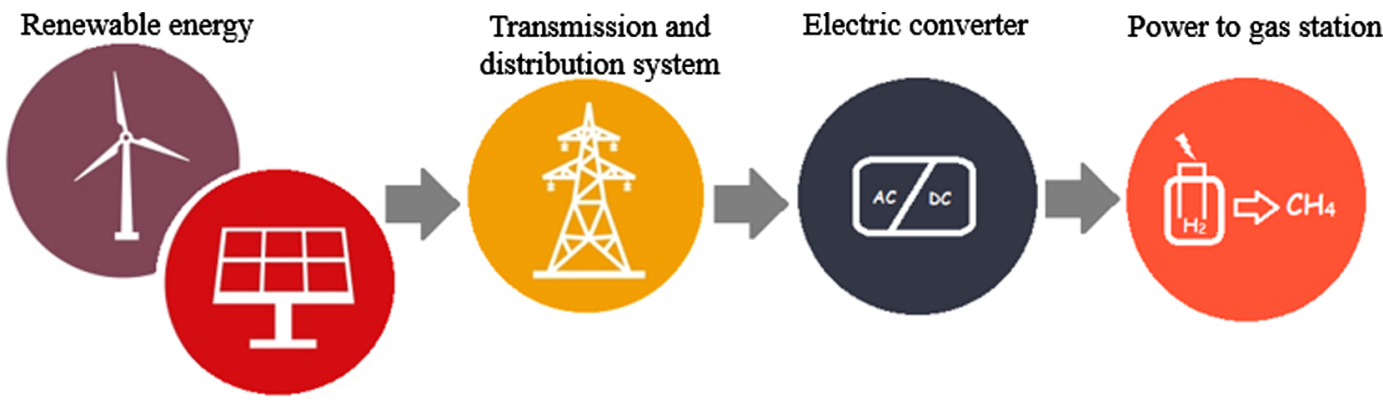

Fig. 2. Diagram of power-to-gas (P2G) energy storage.

wastewater treatment plant - WWTP), effluent from previously operating lab-scale EMG-BES [34] and acetate-based medium (more details in SI, Tables S1-S3). The mixture was changed in proportion over time, as detailed in Table 1, in order to increase the organic matter available in the feed (hence the organic loading rate, OLR) and cycles' duration. Medium 1 was used to fill the entire prototype volume in the first inoculation cycle, which lasted 5 days. Afterwards, the prototype volume was only partially replaced by steps of $5 \mathrm{~L}$. The duration of batch cycles was determined following the trend of electric current consumption, until a steady-state peak current could be detected. In particular, the cycles were closed when current density decreased below a value of $0.2 \mathrm{~A} \mathrm{~m}^{-2}$. The EMG-BES cells were kept at a constant temperature of $32{ }^{\circ} \mathrm{C}$ during all the inoculation process. After 20 batch cycles (corresponding to 62 days), an open circuit voltage (OCV) test was performed (cycle 21), disconnecting the electrodes from the power source. A last cycle at $0.7 \mathrm{~V}$ allowed verifying if the period in OCV had any negative influence on the biological system.

Once the inoculation finished, the hydraulic operation was switched to continuous feeding with municipal wastewater (primary settler effluent, collected at Terrassa WWTP), maintaining an average hydraulic residence time (HRT) of $3.0 \pm 0.5$ days. The wastewater was initially pre-treated as detailed by R. Rodríguez-Alegre et al. [40], however, wastewater saturation with $\mathrm{CO}_{2}$ was not performed, being foreseen for a future experimental step. The wastewater was kept in a pre-treatment tank at ambient temperature, where $\mathrm{NaOH}$ was added $(35 \mathrm{~mL}$ of $3 \mathrm{M}$ $\mathrm{NaOH}$ solution per $\mathrm{L}$ of wastewater) and the resulting precipitates were let to settle. After $24 \mathrm{~h}$, wastewater was poured to a homogenization tank of $50 \mathrm{~L}$ maintained at $4{ }^{\circ} \mathrm{C}$. Here, the $\mathrm{pH}$ was neutralized by addition of $26 \mathrm{mmol} \mathrm{CH}_{3} \mathrm{COOH}$ per liter of wastewater, increasing organic matter concentration to $1.3 \mathrm{~g} \mathrm{CODL}^{-1}$ and conductivity to $10.2 \mathrm{mS} \mathrm{cm}^{-1}$. A variable quantity of $\mathrm{H}_{2} \mathrm{SO}_{4}$ was used to reach a uniform $\mathrm{pH}$ of $7.5\left(41 \pm 14 \mathrm{mmol} \mathrm{H}_{2} \mathrm{SO}_{4} \mathrm{~L}^{-1}\right)$. More details of wastewater characteristics, before and after pre-treatment, are available in SI, Table S4. During continuous operation, the prototype was operated at different conditions, varying the voltage and temperature parameters as detailed in Table 2.

\subsection{Liquid and gas phase characterization}

Samples of influent and effluent wastewater were collected twice a week, and characterized according to Standard Methods in terms of $\mathrm{pH}$, conductivity (by HQ40 multimeter, Hach Lange, Spain) and chemical oxygen demand (COD, by LCK 514 kits, Hach Lange, Spain) [41]. The organic matter removal efficiency ( $\eta \mathrm{COD}$ ) was determined by Eq. (1).

$\eta C O D=\frac{\mathrm{COD}_{\mathrm{IN}}-\mathrm{COD}_{\mathrm{OUT}}}{\mathrm{COD}_{\mathrm{IN}}} \cdot 100$

where $\mathrm{COD}_{\mathrm{IN}}$ is the $\mathrm{COD}$ concentration at the beginning of a batch cycle (during inoculation) or the concentration of influent wastewater (during continuous feeding operation), while $\mathrm{COD}_{\text {OUT }}$ is the COD concentration at the end of the cycle (inoculation) or the one of effluent wastewater (operation).

Gas samples were collected regularly. Their volumetric content in terms of $\mathrm{CO}_{2}, \mathrm{CH}_{4}, \mathrm{O}_{2}$ and $\mathrm{N}_{2}$ was determined by a Micro-GC (Agilent 490, Spain) with dual channel cabinet and thermal conductivity detector. During the inoculation period, $\mathrm{CH}_{4}$ production was evaluated in terms of accumulated gas volume at the end of each batch cycle. On the other hand, during continuous feeding operation the $\mathrm{CH}_{4}$ production rate was determined by multiplying the gas production rate (measurable through the external collection chambers) by its relative $\mathrm{CH}_{4}$ content. A normalized value of $\mathrm{CH}_{4}$ production was achieved dividing it by cathode surface $\left(0.77 \mathrm{~m}^{2}\right)$.

\subsection{Electrical monitoring of EMG-BES prototype}

The 45 EMG-BES cells composing the prototype were connected in parallel. The current (I) consumed by each cell was calculated through Ohm's law by measuring the voltage drop across $4.8 \Omega$ shunt resistances, installed in series to each cell. Three 16-channels DAQ boards (PicoLog 1216, Farnell, Spain) were adopted at this purpose. Current was evaluated in terms of single cell $\left(\mathrm{I}_{\mathrm{i}, \mathrm{j}}\right)$, reactor module $\left(I_{i}=\sum_{j=1}^{3} I_{i, j}\right.$ with $i=1-15)$ and complete stack $\left(I=\sum_{i=1}^{15} I_{i}\right)$. Current density was (a)

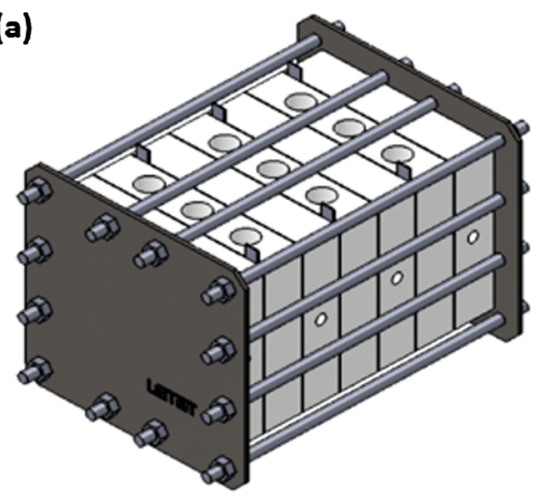

(b)

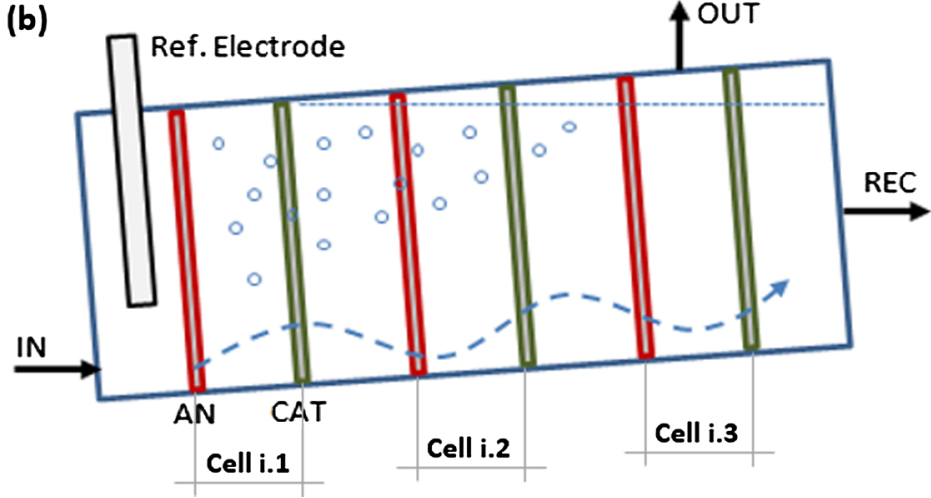

Fig. 3. Design of the individual reactor module: (A) isometric view; (B) cross sectional view. 
Table 1

Composition and characteristics of the media adopted for prototype feeding during inoculation period.

\begin{tabular}{|c|c|c|c|c|c|c|}
\hline \multirow[t]{2}{*}{ Medium } & \multirow[t]{2}{*}{ Time } & \multicolumn{3}{|c|}{ Composition } & \multirow{2}{*}{$\begin{array}{l}\text { Sodium acetate } \\
\text {-concentration in } \\
\text { mineral medium } \\
\left(\mathrm{g} \mathrm{L}^{-1}\right)\end{array}$} & \multirow{2}{*}{$\begin{array}{l}\text { Concentration of } \\
\text { organic matter } \\
\left(\mathrm{g} \mathrm{O}_{2} \mathrm{~L}^{-1}\right)\end{array}$} \\
\hline & & $\begin{array}{l}\text { Mineral } \\
\text { medium } \\
(\% \mathrm{v} / \mathrm{v})\end{array}$ & $\begin{array}{l}\text { Anaerobic } \\
\text { sludge } \\
(\% \mathrm{v} / \mathrm{v})\end{array}$ & $\begin{array}{l}\text { Effluent of } \\
\text { EMG-BES } \\
(\% \mathrm{v} / \mathrm{v})\end{array}$ & & \\
\hline M1 & $\begin{array}{l}\text { Cycles 1-3 } \\
\text { (days 0-8) }\end{array}$ & 50 & 25 & 25 & 2.5 & $2.7 \pm 0.7$ \\
\hline M2 & $\begin{array}{l}\text { Cycles 4-9 } \\
\text { (days 9-22) }\end{array}$ & 50 & 25 & 25 & 5 & $4.7 \pm 0.3$ \\
\hline M3 & $\begin{array}{l}\text { Cycles } 10-22 \\
\text { (days 23-68) }\end{array}$ & 75 & 25 & 0 & 5 & $5.8 \pm 1.5$ \\
\hline
\end{tabular}

obtained dividing it by cathode surface. The distribution of current within each reactor module was evaluated in percentage terms, through the parameter "I ratio" (Eq. (2)).

I ratio $=\frac{\sum_{i=1}^{15} I_{i, j}}{I} \cdot 100$ with $j=1,2,3$

Power demand of the EMG-BES stack was calculated by multiplying consumed current by applied voltage. The individual electrode potentials were measured periodically in comparison with $\mathrm{Ag} / \mathrm{AgCl}$ reference electrodes ( + 0.197 V vs SHE, Xi'an Yima Opto-electrical Technology, China), installed inside each reactor module.

\subsection{Coulombic and energy storage efficiency}

Cathode Coulombic efficiency $\left(\mathrm{CE}_{\mathrm{cat}}\right)$, representing the proportion between the electrons recovered as $\mathrm{CH}_{4}$ and consumed current, and anode Coulombic efficiency $\left(\mathrm{CE}_{\mathrm{an}}\right)$, representing the proportion between the current and the electrons available by organic matter oxidation, were determined by Eqs. (3) and (4) respectively.

\begin{tabular}{|c|c|c|c|}
\hline Electrode & Inoculation period & Continuous feeding period & Eq. \\
\hline Anode & $\mathrm{CE}_{a n}=\frac{M_{\mathrm{O} 2} \cdot \int_{\mathrm{t} 0}^{\mathrm{tf}} \mathrm{Idt}}{\mathrm{F} \cdot \mathrm{b} \cdot \mathrm{Vr} \cdot \Delta \mathrm{COD}}$ & $\mathrm{CE}_{a n}=\frac{M_{\mathrm{O} 2} \cdot I}{\mathrm{~F} \cdot \mathrm{b} \cdot \mathrm{Q} \cdot \Delta \mathrm{COD}}$ & (3) \\
\hline Cathode & $\mathrm{CE}_{c a t}=\frac{\mathrm{c} \cdot \mathrm{F} \cdot \mathrm{CH}_{4 \_} \text {tot }}{\operatorname{Vm}_{\left(25^{\circ} \mathrm{C}\right)} \cdot \int_{\mathrm{t} 0}^{\mathrm{tf}} \mathrm{Idt}}$ & $\mathrm{CE}_{\text {cat }}=\frac{\mathrm{c} \cdot \mathrm{F} \cdot \mathrm{CH}_{4 \_} \text {prod }}{\operatorname{Vm}_{\left(25^{\circ} \mathrm{C}\right)^{-I}}}$ & (4) \\
\hline
\end{tabular}

In these equations $\mathrm{M}_{\mathrm{O} 2}$ is the molecular weight of $\mathrm{O}_{2}\left(32 \mathrm{~g} \mathrm{~mol}^{-1}\right)$, I is the electrical current, $\mathrm{Vr}$ is the prototype volume and $\mathrm{F}$ is the Faraday constant $\left(96,485 \mathrm{C} \mathrm{mol}^{-1}\right)$. The term $\mathrm{b}$ refers to the number of $\mathrm{e}^{-}$ moles exchanged per mole of COD (4), while $c$ defines the $\mathrm{e}^{-}$moles required to reduce $1 \mathrm{~mol}$ of $\mathrm{CO}_{2}$ to $\mathrm{CH}_{4}$ (8). The term $\Delta \mathrm{COD}$ is equal to the difference of COD between the beginning $\left(\mathrm{t}_{0}\right)$ and the end $\left(\mathrm{t}_{\mathrm{f}}\right)$ of a batch cycle, during the inoculation period. The same term $(\Delta \mathrm{COD})$ refers to the COD difference between influent and effluent wastewater, during continuous feeding period. Finally, $\mathrm{Q}$ is the feeding rate and $\mathrm{Vm}_{\left(25^{\circ} \mathrm{C}\right)}$ is the molar volume of an ideal gas at $25^{\circ} \mathrm{C}$ and $1 \mathrm{~atm}$ $\left(24.5 \mathrm{~L} \mathrm{~mol}^{-1}\right)$.

The maximum theoretical $\mathrm{CH}_{4}$ production by electromethanogenesis was estimated rearranging Eq. (4) and considering a cathodic Coulombic efficiency of $100 \%$. On the other hand, the specific energy consumption of EMG-BES reactors (in $\mathrm{kWh} \mathrm{m}^{-3} \mathrm{CH}_{4}$ ) was calculated dividing consumed electric power by $\mathrm{CH}_{4}$ production rate (this evaluation was performed only during the continuous feeding operation).
Considering Gibbs free energy of $\mathrm{CH}_{4}$ oxidation $\left(\Delta \mathrm{G}_{\mathrm{CH} 4}\right.$, equal to $11 \mathrm{kWh} \mathrm{Nm}^{-3} \mathrm{CH}_{4}$ ), it was possible to evaluate the energy storage efficiency of the prototype (EE) for the two tested temperatures of 32 and $25^{\circ} \mathrm{C}$. The surplus $\mathrm{CH}_{4}$ production obtained bioelectrochemically (i.e. applying voltage) was divided by the electricity consumption of the power source (Eq. (5)).

$E E=\frac{\left(\mathrm{CH}_{4}^{c c}-\mathrm{CH}_{4}^{\text {ocv }}\right) \cdot \Delta G_{C H 4}}{E_{\text {cell }} \cdot I} \cdot 100$

In this equation, $\mathrm{CH}_{4}{ }^{\mathrm{cc}}$ represents $\mathrm{CH}_{4}$ production rate in closed circuit (condition 1.1 and 3, Table 2) while $\mathrm{CH}_{4}{ }^{\text {ocv }}$ stands for $\mathrm{CH}_{4}$ production rate in OCV (condition 2 and 4, Table 2). The term $\mathrm{E}_{\text {cell }}$ is the applied voltage when the prototype was in closed circuit (equal to $0.7 \mathrm{~V})$.

\subsection{Scanning electron microscopy (SEM)}

One reactor module (n. 15) was opened at the end of the experiment, in order to check the general status of bioelectrodes and current collectors. Samples of each electrode ( 3 anodes and 3 cathodes) were collected for scanning electron microscopy (SEM) analysis of their surface (SEM TOUCHSCOPE JEOL JSM-6010LV, Izasa S.A., Spain). Samples were vacuum dried for $24 \mathrm{~h}$, put in a laboratory drier for additional $72 \mathrm{~h}$ and coated with $4 \mathrm{~nm}$ of gold before SEM observation.

\subsection{Electric characterization and modelling}

The I-V curve of prototype was obtained once EMG-BES stack reached steady-state conditions, in order to model its electric behavior. Before analyzing the I-V curve, a preliminary test was performed to determine the time needed by the prototype to stabilize on a new

Table 2

Operation conditions tested along the experiment $(\mathrm{OCV}=$ open circuit voltage).

\begin{tabular}{llll}
\hline Condition & Time (day) & Applied voltage $(\mathrm{V})$ & Temperature $\left({ }^{\circ} \mathrm{C}\right)$ \\
\hline 1.1 & $69-118$ & 0.7 & 32 \\
2 & $119-128$ & OCV & 32 \\
1.2 & $129-132$ & 0.7 & 32 \\
3 & $133-149$ & 0.7 & 25 \\
4 & $150-156$ & OCV & 25 \\
\hline
\end{tabular}


applied voltage. The test was conducted varying the applied voltage from its nominal value $(0.7 \mathrm{~V})$ to $0.8 \mathrm{~V}$ and measuring the current every $10 \mathrm{~s}$. Based on the results of this test, the I-V curve was traced by using a potentiostat (SP-150, BioLogic), connected to a high-current booster. Voltage was varied gradually from 0 to $1.25 \mathrm{~V}$, and consumed current was measured every 2 min.

The nonlinear behavior of the EMG-BES stack was simulated in MatLab by a series of black-box models, which output was compared with the experimental data in order to choose the best model representation. Four models were tested for EMG-BES stack modelling. Eqs. (6)-(9) represent the transfer functions of the different equivalent models.

$1^{\text {st }}$ order model $\frac{I}{V}=\frac{1024 s+0.3401}{s+0.0009131}$

$2^{\text {nd }}$ order model $\frac{I}{V}=\frac{s^{2}+3.528 s+0.0006357}{s^{2}+0.004418 s+1.722 \cdot 10^{-6}}$

$3^{\text {rd }}$ order model $\frac{I}{V}=\frac{1074 s^{3}+0.2681 s^{2}+7.844 \cdot 10^{-6} s+7.835 \cdot 10^{-9}}{s^{3}+0.0009803 s^{2}+2.02 \cdot 10^{-8} s+1.979 \cdot 10^{-11}}$

$$
\begin{aligned}
& 4^{\text {th }} \text { order model } \frac{I}{V} \\
& =\frac{1269 s^{4}+2.319 s^{3}+0.001461 s^{2}+1.002 \cdot 10^{-6} s+3.671 \cdot 10^{-10}}{s^{4}+0.004306 s^{3}+2.774 \cdot 10^{-6} s^{2}+1.914 \cdot 10^{-9} s+9.603 \cdot 10^{-13}}
\end{aligned}
$$

In these equations, $\mathrm{V}$ is the input voltage of the EMG-BES stack, I is the resulting stack current and the Laplace operator is represented by the well-known 's' term. The model will be used in a future experimental step to design the electric converter for grid integration of EMGBES, and effective energy storage application of the technology.

\section{Results and discussion}

\subsection{Inoculation process}

The prototype was inoculated in batch mode with a mixture of synthetic mineral medium, anaerobic sludge and effluent from a running lab-scale EMG-BES. During each batch cycle, a peak in the current density could be detected. This peak had a plateau around $0.9 \mathrm{~A} \mathrm{~m}^{-2}$, indicating the effective inoculation by electro-active bacteria taking place at the anode (Fig. 4). In addition, the $\mathrm{CE}_{\text {an }}$ increased from $33 \%$ (cycle 2) to $61 \%$ (cycle 20), confirming that exoelectrogenic bacteria were growing on the anode (SI, Fig. S2-b).

The $\mathrm{CH}_{4}$ production increased during this period, up to $1.3 \mathrm{~L} \mathrm{~m}^{-2}$ cycle $^{-1}$ in cycle 14 (SI, Fig. S2-a). This was due to both (i) the increase of organic matter concentration in the feed, going from M1 to M3 (see Table 1 for details), and (ii) the growth of methanogens. The $\mathrm{CH}_{4}$ production stabilized around $0.5 \mathrm{~L} \mathrm{CH}_{4} \mathrm{~m}^{-2}$ cycle ${ }^{-1}$ between cycles 16 and 20 while $\mathrm{CE}_{\text {cat }}$, representing the amount of electricity going to $\mathrm{CH}_{4}$, was more variable $(22 \pm 9 \%)$. The average $\mathrm{CH}_{4}$ content of the biogas was $38 \pm 10 \%$, while the remaining volume was $\mathrm{N}_{2}(60 \pm 11 \%), \mathrm{CO}_{2}$ $(1.5 \pm 0.7 \%)$ and $\mathrm{O}_{2}(0.7 \pm 1 \%)$ (SI, Table S5). The presence of $\mathrm{N}_{2}$ was due to air intrusion in the reactor, which could not be maintained airtight during inoculation. However, the ratio between $\mathrm{O}_{2}$ and $\mathrm{N}_{2}$ of produced biogas was lower than that of atmospheric air ( 0.01 compared with 0.27 ). The $\mathrm{O}_{2}$ content of the air entering in the reactor was likely reduced to water at the cathode or consumed by heterotrophic bacteria, that were also present due to the mixed microbial culture used as inoculum.
The cathode potential $\left(\mathrm{E}_{\text {cat }}\right)$ varied along the batch cycles: $\mathrm{E}_{\text {cat }}$ was around $-0.83 \pm 0.06 \mathrm{~V}$ vs SHE during first part of cycle (when organic matter concentration was higher), and it increased to $-0.66 \pm 0.02 \mathrm{~V}$ vs SHE at the end of cycle (when organic matter concentration was lower).

\subsection{Batch tests}

Batch cycle $\mathrm{n}^{\circ} 17$ was analyzed in more detail in terms of current density, $\mathrm{CH}_{4}$ production and COD evolution (Fig. 5). The current density remained around $0.83 \mathrm{~A} \mathrm{~m}^{-2}$ for the first $22 \mathrm{~h}$ of the cycle, while organic matter gradually decreased from $1.24 \mathrm{~g}_{\text {-COD L }}{ }^{-1}$ to $0.60 \mathrm{~g}$-COD $\mathrm{L}^{-1}$ (52\% removal). The $\mathrm{CH}_{4}$ production reached $0.31 \mathrm{~L} \mathrm{~m}^{-2}$ in the same time interval, corresponding to the $60 \%$ of total $\mathrm{CH}_{4}$ production in the cycle. Below this critical COD value, the current decreased from 0.8 to $0.2 \mathrm{~A} \mathrm{~m}^{-2}$ in around $24 \mathrm{~h}$. These observations indicate that continuous operation of the prototype at an HRT of $22 \mathrm{~h}$ could likely guarantee the best performance in terms of current density consumption and $\mathrm{CH}_{4}$ production rate. At the end of the batch cycle $(48 \mathrm{~h})$, the organic matter concentration reached $0.45 \mathrm{~g}^{-} \mathrm{COD} \mathrm{L}{ }^{-1}$ corresponding to a removal efficiency of $59 \%$ while $\mathrm{CH}_{4}$ production reached $0.5 \mathrm{~L} \mathrm{~m}^{-2}$.

The batch cycle $n^{\circ} 21$ was conducted in OCV condition, in order to assess if $\mathrm{CH}_{4}$ production was bioelectrochemically driven (SI, Fig. S3). The cycle lasted 2 days and the accumulated biogas production accounted only for $0.06 \mathrm{~L} \mathrm{~m}^{-2}$, with a very low content of $\mathrm{CH}_{4}(3.5 \%)$. The result indicated that $\mathrm{CH}_{4}$ production in closed circuit condition (applying voltage) was bioelectrochemically driven, and only residual acetate was converted to $\mathrm{CH}_{4}$ by acetoclastic methanogens. On the other hand, organic matter followed similar dynamics than the test performed at $0.7 \mathrm{~V}$, reaching $60 \%$ removal efficiency after $48 \mathrm{~h}$. It can be inferred that non-exoelectrogenic bacteria were also present in the reactor (most likely fermenters), with the capacity to consume the organic matter at a similar rate than exoelectrogens, although not producing methane.

After the OCV period, a last cycle at $0.7 \mathrm{~V}$ was conducted to verify if the EMG-BES prototype was resilient to short-term power supply fluctuations. The production of $\mathrm{CH}_{4}$ and consumption of current reached similar values than those before the OCV test (Fig. 4).

\subsection{Continuous feeding operation}

Condition 1.1) On day 69, the prototype was hydraulically connected to the homogenization tank containing real wastewater, which was continuously fed at an OLR of $0.46 \pm 0.07 \mathrm{Kg} \mathrm{COD} \mathrm{m}^{-3}$ day $^{-1}$, corresponding to an HRT of $3.0 \pm 0.5$ days. The voltage and temperature were maintained at same values of inoculation.

The current density initially remained near $0.9 \mathrm{~A} \mathrm{~m}^{-2}$, a value similar to that obtained in the peaks from the last cycles of inoculation. Then, the current progressively decreased to $0.5 \mathrm{Am}^{-2}$, while $\mathrm{CH}_{4}$

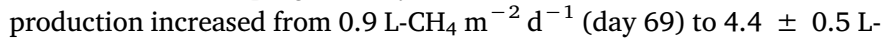
$\mathrm{CH}_{4} \mathrm{~m}^{-2} \mathrm{~d}^{-1}$ (day 90-118). Consequently, $\mathrm{CE}_{\text {cat }}$ increased from $40 \%$ to values higher than $100 \%$. The cathode potential remained stable at $-0.86 \pm 0.02 \mathrm{~V}$ vs SHE during operation. On the other hand, $\mathrm{CE}_{\mathrm{an}}$ decreased from $63 \%$ (day 72) to $29 \pm 4 \%$ (day 90-118). These observations may indicate that acetoclastic methanogenic microbes were growing in the electrolyte medium, competing with electro-active biofilm for acetate as unique substrate (therefore, $\mathrm{CE}_{\mathrm{an}}$ decreased). Acetoclastic methanogens added their $\mathrm{CH}_{4}$ production to that of hydrogenotrophic methanogens already present at the cathode. As a result, $\mathrm{CE}_{\text {cat }}$ lost its physical meaning when turning to values higher than 


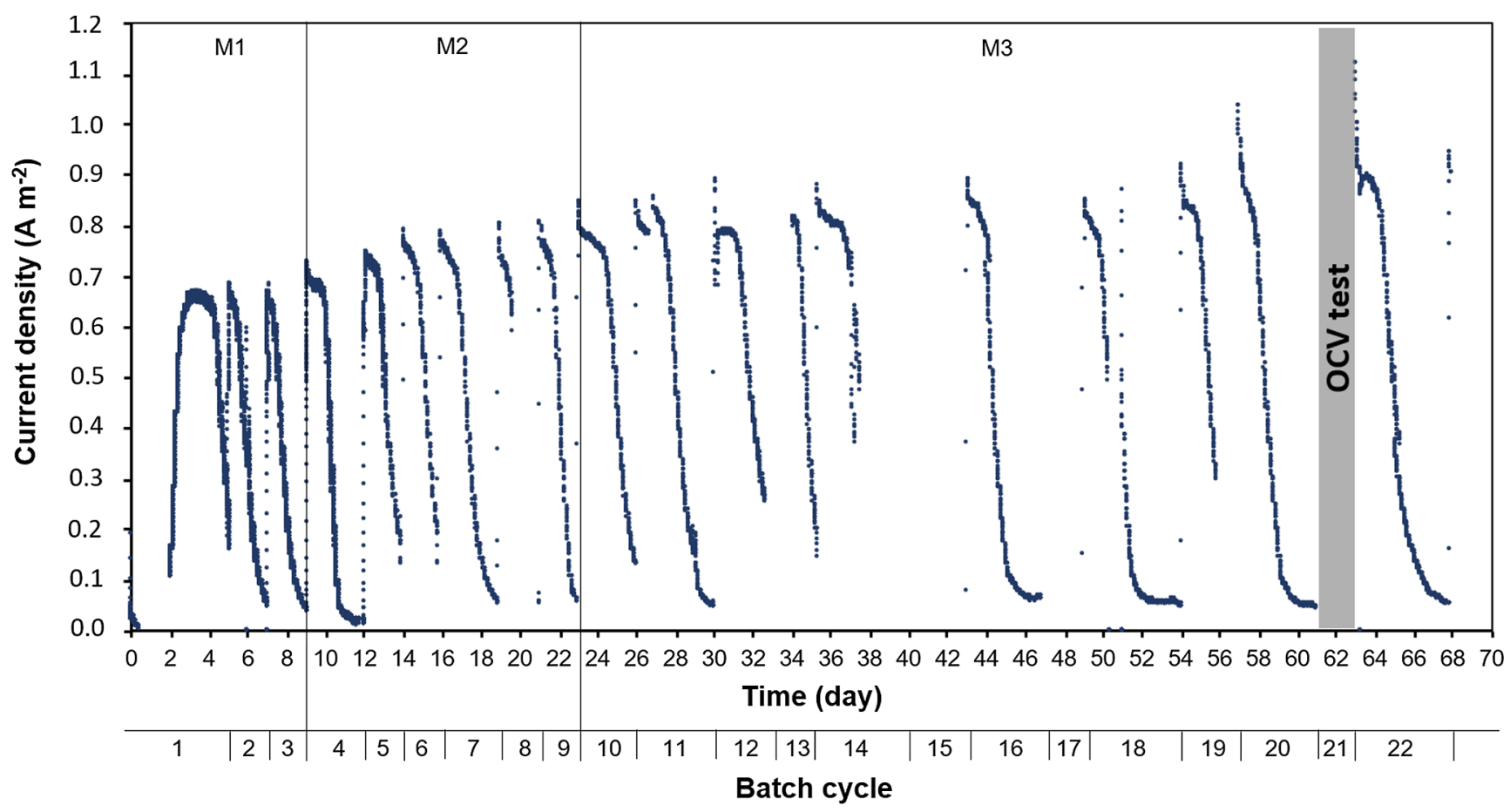

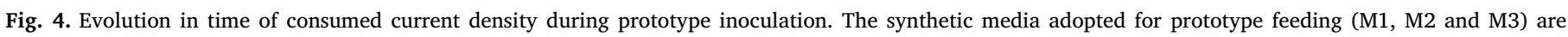
reported for reference.

$100 \%$ (i.e. $\mathrm{CH}_{4}$ production was higher than that achievable only by EMG). In this scenario, it became more challenging to measure the current going to $\mathrm{CH}_{4}$, and Eq. (4) only gave a rough (and optimistic) estimation of it. Indeed, current could have been consumed at the cathode by competitive terminal electron acceptors like oxygen and sulphate. Fig. 6 displays the results obtained during this experimental period (see also SI, Table S6). The current distributed in an uneven way between the cells composing each reactor module, slightly increasing going from the inlet to the outlet section of the module. On average, cells i. 1 consumed a $30 \%$ of total current, cells i. 2 a $33 \%$ and cells i. 3 a $38 \%$ (see Fig. 3 and SI, Table S7).

The effluent COD concentration decreased from $0.78 \mathrm{~g} \mathrm{~L}^{-1}$ (day 72, first day after inoculation period) to $0.40 \pm 0.09 \mathrm{~g} \mathrm{~L}^{-1}$ (days 111-118), corresponding with an increase of COD removal efficiency

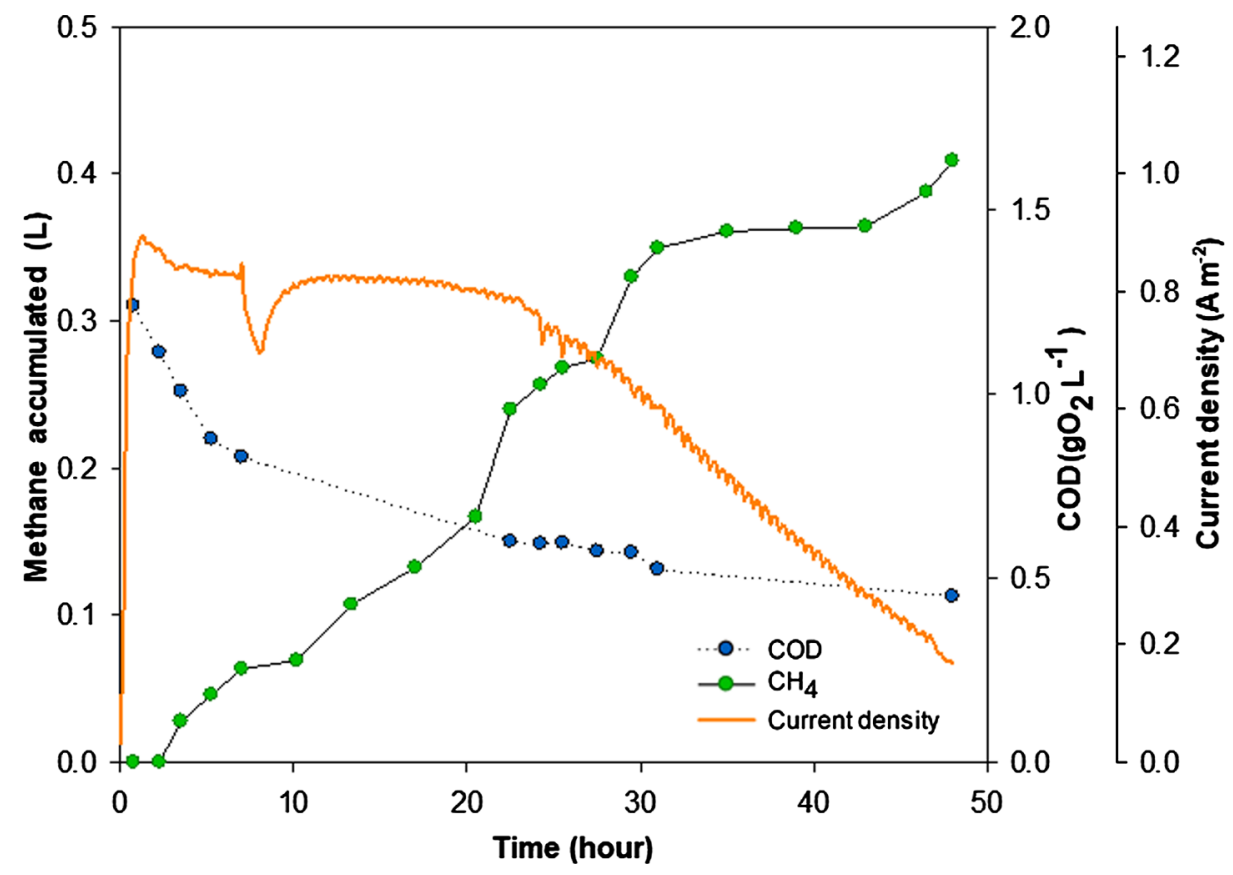

Fig. 5. Evolution in time of $\mathrm{CH}_{4}$ production, current density and COD concentration for batch cycle $n^{\circ} 17$ (at $0.7 \mathrm{~V}$ ). 
(a)

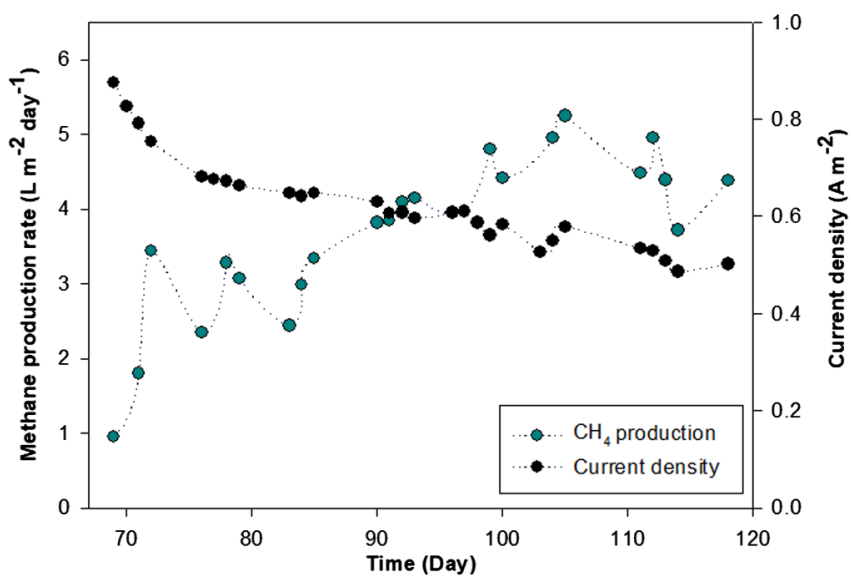

(b)

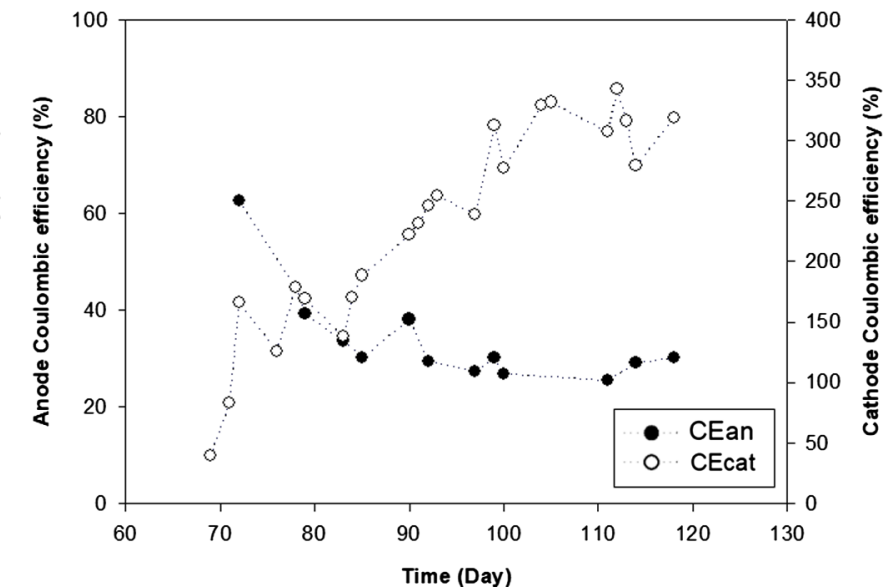

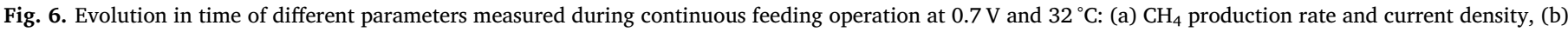
$\mathrm{CE}_{\mathrm{an}}$ and $\mathrm{CE}_{\mathrm{cat}}$, respectively.

from $42 \%$ (day 72 ) to $72 \pm 7 \%$ (day $90-118$ ). These results were similar than those achieved by Brown et al. [42] at similar OLR and feeding conditions. This decrease of the organic matter concentration in the reactor was partly responsible for the reduction of current density, together with microbial competition between electro-active bacteria and acetoclastic methanogens.

Moreover, chemical fouling on cathodes likely reduced the reduction capacity of electro-active bacteria, causing a decrease in mass transfer rates of ionic species [43]. This consideration was partly confirmed by SEM analysis of cathode samples (see Section 3.5), but it still requires additional tests.

At the stationary phase of condition 1.1 (day 90-118), the theoretical (and optimal) $\mathrm{CH}_{4}$ production by EMG represented only $32 \%$ of measured production (Fig. 7). The volumetric content of $\mathrm{CH}_{4}$ in produced biogas was $87 \pm 3 \%$, while $\mathrm{CO}_{2}$ was present only at $0.9 \pm 0.8 \%$. The content of $\mathrm{N}_{2}$ represented $10 \pm 5 \%$ of the volume, while $\mathrm{O}_{2}$ was detected only in trace amounts. The low presence of $\mathrm{CO}_{2}$ was due to the high $\mathrm{pH}$ of the effluent $(8.5 \pm 0.2)$, allowing $\mathrm{CO}_{2}$ (produced by acetate oxidation) to remain dissolved in the effluent, mainly as bicarbonate. Therefore, the biogas produced had a high quality, near biomethane standards.

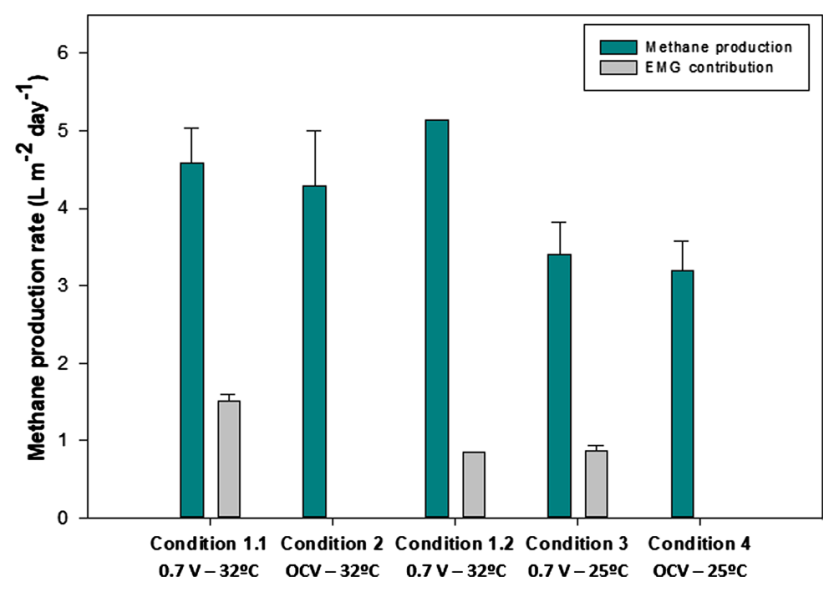

Fig. 7. Measured $\mathrm{CH}_{4}$ production rate compared with theoretical EMG-driven production. Average \pm standard deviation values are reported, for different operation conditions tested (condition 1.1 refers to day 90 to 118).

\subsection{Voltage and temperature effects}

Condition 2) Once EMG-BES prototype reached a stationary operation, OCV condition (days 119-128) was tested again while keeping the temperature at $32{ }^{\circ} \mathrm{C}$. The objective was to test system resiliency to a temporary absence of electric power. This aspect was crucial, since the technology should be powered by fluctuant RES surplus energy. Previous studies observed that OCV periods longer than 5 days could affect microbial populations' dynamics in microbial electrolysis cells [44]. Still, normal microbial electro-activity could be recovered after a few days of voltage application.

In this case, the $\mathrm{CH}_{4}$ production in OCV decreased of $9.2 \%$ compared to previous period at $0.7 \mathrm{~V}$ (days 90-118), reaching an average of

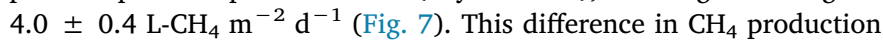
was lower than the theoretical EMG contribution, indicating (i) that acetoclastic methanogenesis was favored in OCV condition, and (ii) that EMG contribution was likely overestimated. In the biogas mixture, $\mathrm{CH}_{4}$ content remained at $86 \pm 2 \%, \mathrm{CO}_{2}$ at $1.4 \pm 1 \%$ and $\mathrm{N}_{2}$ at $12 \pm 7 \%$ $\left(\mathrm{O}_{2}\right.$ was not detected). The $\mathrm{CO}_{2}$ content remained low due to the basic $\mathrm{pH}$ of wastewater effluent $(8.4 \pm 0.2)$, which did not change considerably in OCV condition. On the other hand, organic matter removal efficiency decreased from $71 \%$ to $60 \%$ under OCV conditions, meaning that the electrochemical system had an influence on the overall substrate oxidation rate. Indeed, exoelectrogenic bacteria could not take part in organic matter oxidation, reducing the overall microbial COD removal capacity of the reactor (SI, Fig. S4 and Table S6).

These observations show that voltage application in EMG-BES reactors can accelerate traditional anaerobic digestion processes (hydrolysis, acidogenesis, acetogenesis, methanogenesis), thanks to the activity of exoelectrogenic bacteria at the anode and hydrogenotrophic methanogens at the cathode. The latter are characterized by faster kinetics and growth rate than acetoclastic ones [25].

Condition 1.2) After the OCV test, the previous operational conditions were restored for a couple of days and $\mathrm{CH}_{4}$ production rate went back to values similar than those of condition 1.1 (SI, Fig. S4 and Table S6). The biogas composition did not change significantly $\left(87.3 \% \mathrm{CH}_{4}\right)$, while organic matter removal efficiency slightly increased to $81 \%$. However, the current density stabilized at a lower value than that of condition 1.1, decreasing from $0.5 \mathrm{~A} \mathrm{~m}^{-2}$ (day 118) to $0.3 \mathrm{~A} \mathrm{~m}^{-2}$ (day 132). Coherently, $\mathrm{CE}_{\text {an }}$ decreased from $30 \%$ to $11 \%$ while $\mathrm{CE}_{\text {cat }}$ increased from $286 \%$ to $624 \%$. The fraction of $\mathrm{CH}_{4}$ produced by EMG decreased from $34 \%$ (day $90-118$ ) to $16 \%$ (day 129-132) (Fig. 7). These observations indicate that electro-active bacteria were growing slower than acetoclastic methanogens during the OCV period. 
Comparing the results obtained before and after the OCV test, it can be inferred that COD was consumed through different pathways, although with similar efficiency in $\mathrm{CH}_{4}$ production. Th erefore, th e prototype demonstrated a certain resilience to power supply fluctuations, although the OCV period likely affected microbial populations' activity.

Condition 3) On day 133 , the temperature was reduced to $25{ }^{\circ} \mathrm{C}$ in order to: (i) slow down the growth of acetoclastic methanogens compared to that of electro-active bacteria, and (ii) test the system at a lower energy demand. There are no available studies in literature describing the effect of temperature over microbial consortia colonizing EMG-BES reactors, especially regarding the competition between electro-active bacteria and acetoclastic methanogens. However, previous studies investigated temperature effect o $\mathrm{n} t$ he $\mathrm{g}$ eneration of electricity by microbial fuel cells, showing that exoelectrogenic bacteria are able to adapt to different temperature [45]. Methanogenic microbes are known to be more sensitive to this parameter.

In this experimental condition, $\mathrm{CH}_{4}$ production at $25{ }^{\circ} \mathrm{C}$ decreased by $33 \%$ when compared to that achieved at $32^{\circ} \mathrm{C}$ (condition 1.2 ), reaching an average of $3.4 \pm 0.4 \mathrm{~L}^{-} \mathrm{CH}_{4} \mathrm{~m}^{-2} \mathrm{~d}^{-1}$ (133-149). However, the current density remained near $0.3 \mathrm{~A} \mathrm{~m}^{-2}$ and, thus, $\mathrm{CE}_{\mathrm{an}}$ increased from $11 \%$ (condition 1.2 ) to $16 \pm 3 \%$, confirming that $t$ he lower temperature favored electro-active bacteria growth versus acetoclastic methanogens (SI, Fig. S4). The current distributed between the individual cells of reactor modules on a similar fashion than that detected during condition 1.1 (SI, Table S8). In terms of biogas composition, $\mathrm{CH}_{4}$ increased to $91 \pm 2 \%$, while $\mathrm{CO}_{2}$ remained on low values of $0.1 \pm 0.1 \%$. Organic matter removal efficiency decreased from $80 \%$ (condition 1.2) to $64 \pm 6 \%$, due to the slower microbial metabolism at lower temperature.

Condition 4) A final OCV test was performed at $25{ }^{\circ} \mathrm{C}$ to determine the effect of $\mathrm{OCV}$ on $\mathrm{C}_{4}$ p roduction. At this temperature, $\mathrm{C}_{4}$ production decreased by $6 \%$ compared to operation at $0.7 \mathrm{~V}$ and $25^{\circ} \mathrm{C}$, reaching an average of $3.2 \pm 0.4 \mathrm{~L}_{-} \mathrm{CH}_{4} \mathrm{~m}^{-2} \mathrm{~d}^{-1}$. Like previous OCV test (condition (2)), the $\mathrm{CH}_{4}$ content in generated biogas remained high, around $90 \pm 2 \%$.

In terms of volumetric gas production rate, the EMG-BES reactor produced near $0.1 \mathrm{~m}^{3}-\mathrm{CH}_{4} \mathrm{~m}^{-3} \mathrm{~d}^{-1}$ at $32{ }^{\circ} \mathrm{C}$ and a $20 \%$ less at $25^{\circ} \mathrm{C}$. These values are lower than those achievable in biogas plants (around 0.5-1 $\mathrm{m}^{3}-\mathrm{CH}_{4} \mathrm{~m}^{-3} \mathrm{~d}^{-1}$ ) [46], due to the low OLR applied (0.5 $\mathrm{kg}$ COD $\mathrm{m}^{-3} \mathrm{~d}^{-1}$ ) compared to the 8-20 kg COD m $\mathrm{m}^{-3} \mathrm{~d}^{-1}$ typically adopted for sludge anaerobic digesters [47].

\subsection{Microscopy analysis}

Bacterial morphologies on carbon-felt electrodes of module 15 were observed by SEM microscopy once the experimental campaign was finished. The images are reported in SI (Figs. S5 and S6).

Anode images) Sparse aggregates of microbial cells were identified on all anodic electrodes. The carbon fibers were coated by a uniform layer of extracellular polymeric substance (EPS), partly hiding the direct observation of microbial cells. Biofilm-like s tructures c ould be detected on sample A15.2 and, on a greater extent, on sample A15.3, while they were almost absent in sample A15.1. It appeared that microbial growth on the anodes proceeded at a different rate depending on their relative position inside the module, increasing going from inlet to outlet section. The observation is coherent with the distribution of consumed current between the cells composing a module, as previously explained in Section 3.3.

Cathode images) On the other hand, aggregates of crystalized material were identified o $\mathrm{n} t$ he $\mathrm{c}$ athode e lectrodes. $\mathrm{T}$ hese $\mathrm{w}$ ere likely carbonate and/or hydroxide species, appearing on cathode due to the high $\mathrm{pH}$ caused by the reduction reactions hereby taking place. In this case, crystals were present on a higher amount on sample C15.1 and were decreasing gradually on samples C15.2 and C15.3. This precipitation can also explain the progressive reduction of the activity of electro-active bacteria in the cathode.

\subsection{Energy storage efficiency}

The calculation of the energy storage efficiency is necessary to determine the potential of EMG-BES technology as a P2G system. In this context, the energy consumption of the prototype was evaluated and compared to the equivalent electric energy recovered as $\mathrm{CH}_{4}$.

The specific energy consumption of EMG-BES cells was evaluated dividing the electric power consumed by power source by the $\mathrm{CH}_{4}$ production rate. On average, it reached $2.2 \pm 0.3 \mathrm{kWh} \mathrm{m}^{-3} \mathrm{CH}_{4}$ during condition (1) (at $32^{\circ} \mathrm{C}$ ) and $1.6 \pm 0.2 \mathrm{kWh} \mathrm{m}^{-3} \mathrm{CH}_{4}$ during condition 3 (at $25^{\circ} \mathrm{C}$ ), showing that the reduction of operational temperature was beneficial in terms of energy consumption. These values were lower than thermodynamic threshold required for $\mathrm{CO}_{2}$ conversion to $\mathrm{CH}_{4}\left(11 \mathrm{kWh} \mathrm{Nm}^{-3} \mathrm{CH}_{4}\right)$, due to contribution of acetoclastic methanogenesis to total $\mathrm{CH}_{4}$ generation, resulting in an energy storage efficiency overpassing $100 \%$ if only EMG-BES energy consumption was considered.

Therefore, the energy storage efficiency of prototype was evaluated considering the surplus $\mathrm{CH}_{4}$ production obtained applying voltage (versus base production in OCV), which was divided by the electricity consumption of power source like previously shown in Eq. (5). Results are shown in Table 3: around $42-47 \%$ of electric energy applied to EMG-BES cells through power source was retrieved in form of (surplus) $\mathrm{CH}_{4}$ production.

Considering also the electrical consumption of the auxiliary equipment present in the prototype, the energy storage efficiency would drop down to considerably lower values. However, the scale-factor plays an important role in prototype evaluation. Analysis of more mature technologies as electrolysers showed that the energy required by auxiliary equipment generally accounts for $7-40 \%$ of the energy used by the electrochemical cells. This would lead to an energy storage efficiency ranging from $30 \%$ to $40 \%$, still low in the panorama of P2G technologies. Though, the possibility to operate at ambient temperatures and pressures (avoiding a heating system, and/or using solar heating) are likely configuring key advantages of EMG-BES versus other methanation technologies, which will result in a more favorable future scenario for their application in energy storage.

On the other hand, the capital costs of this technology are still high compared with the other available options for energy storage, reaching

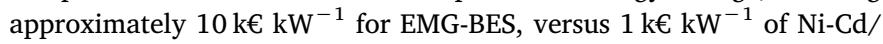
Fe-Cr batteries (assumptions based on authors' experience, calculations not shown). The current low Technology Readiness Level of this technology shall be tackled in future research. Strategies looking for increasing the power density of the system (modifying the reactor architecture) should decrease the overall cost and allow EMG-BES to be competitive (in terms of costs) to current state-of-the-art. In any case, EMG-BES remains an interesting option when dealing with long-term energy storage, and it could benefit of additional revenues due to wastewater treatment and/or carbon valorization.

\subsection{Electric characterization and modelling}

The current density measured during the prototype operation varied between 0.3 and $0.9 \mathrm{~A} \mathrm{~m}^{-2}$, significantly lower than other P2G technologies, meaning that EMG-BES alternative would require higher surfaces (and volumes) to store an equal amount of RES energy surplus. This aspect, together with the complementary need of a wastewater source, makes WWTPs to be ideal locations for this energy storage

Table 3

Evaluation of prototype energy storage efficiency.

\begin{tabular}{lllll}
\hline Temp. $\left({ }^{\circ} \mathrm{C}\right)$ & $\mathrm{CH}_{4}{ }^{\mathrm{cc}}\left(\mathrm{L} \mathrm{m}^{-2} \mathrm{~d}^{-1}\right)$ & $\mathrm{CH}_{4}{ }^{\mathrm{ocv}}\left(\mathrm{L} \mathrm{m}^{-2} \mathrm{~d}^{-1}\right)$ & $\mathrm{I}\left(\mathrm{A} \mathrm{m}^{-2}\right)$ & $\mathrm{EE} \mathrm{( \% )}$ \\
\hline 32 & $4.4 \pm 0.5$ & $4.0 \pm 0.4$ & $0.56 \pm 0.04$ & $47 \%$ \\
25 & $3.4 \pm 0.4$ & $3.2 \pm 0.4$ & $0.31 \pm 0.02$ & $42 \%$
\end{tabular}




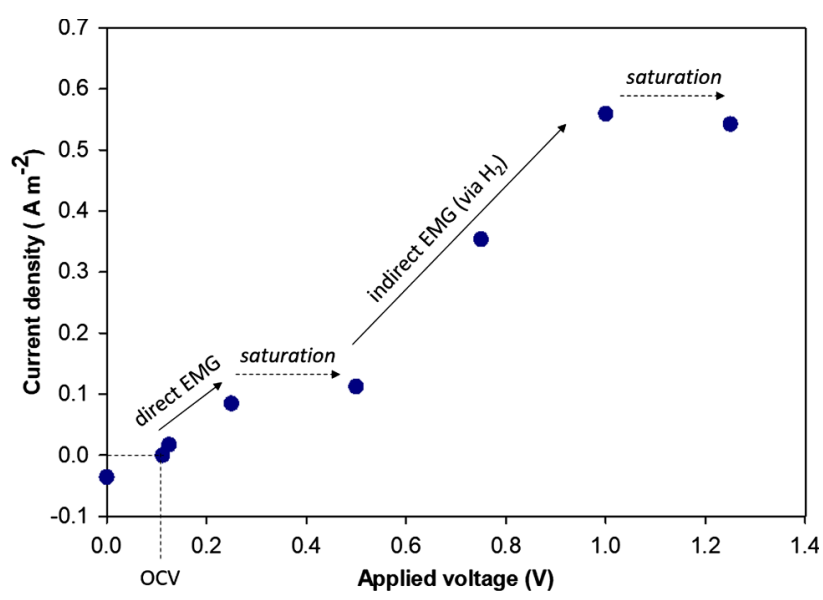

Fig. 8. I-V curve of EMG-BES prototype.

solution.

In terms of electric characterization, it was important to perform an I-V curve of EMG-BES prototype. A preliminary test was performed on day 182 to determine the time required for voltage stabilization to a value different than the nominal one. A stabilization time of $2 \mathrm{~h}$ was enough, as shown in SI, Fig. S7. On day 188, the I-V curve was obtained through a series of stationary conditions at different incremental voltages, from 0 to $1.25 \mathrm{~V}$ (see Fig. 8 and SI, Fig. S8). The current density at steady-state was recorded and used to graph the I-V curve (Fig. 8). The OCV was determined to be $0.112 \mathrm{~V}$. At this point, the current consumed by the EMG-BES cells was zero, and no bioelectrochemical reactions were taking place. At applied voltages higher than OCV, current was consumed by the prototype, while at voltages lower than OCV (down to a short circuit condition) the current was reversing, i.e. electrons were flowing from the cathode to the anode.

Focusing on the positive part of the I-V curve (i.e. voltage $>$ OCV), two sections at higher gradient could be identified, where current density increased significantly when increasing the voltage. On the other hand, two flat sections presented constant current density (saturation zones in Fig. 8). Considering the mechanisms for $\mathrm{CH}_{4}$ production presented in Fig. 1 (direct and indirect EMG), and the relative reduction potentials, it can be speculated that between 0.1 and $0.2 \mathrm{~V}$ applied voltage, direct EMG reaction was likely taking place. At voltages higher than $0.6 \mathrm{~V}$ the $\mathrm{H}_{2}$ evolution reaction summed up, generating $\mathrm{CH}_{4}$ via indirect EMG pathway, and increasing the total current consumption of the prototype. Increasing the applied voltage to more than $1 \mathrm{~V}$ caused instabilities in current consumption, likely due to insufficient electrons uptake from/to the biofilms grown onto both electrodes. Additional tests are required to confirm this theory.

From the electrical point of view, 4 operating conditions can be identified from Fig. 8 for the EMG-BES stack and its associated converter:

(1) OCV condition, for which there is no current circulation, corresponding to "stand-by mode" of the electric converter;

(2) Voltage $<\mathrm{OCV}$, for which current direction is reversed, corresponding to a "forbidden area" that converter must avoid by supplying always a minimum voltage to EMG-BES stack;

(3) Voltage $>$ OCV but $<1 \mathrm{~V}$, for which the value of stack current depends on amplitude of applied voltage, corresponding to the "power mode" of the electric converter;

(4) Voltage $>1 \mathrm{~V}$ (saturation), where current is almost constant, and EMG-BES stack become unstable at further increments of applied voltage. Converter must not enter in this area.

The converter must be designed to work in area (1) during standby mode and area (3) during power mode. The maximum stack current is another critical factor to design the converter. It was observed that, when a step voltage is applied to the EMG-BES stack, a current overshoot around $100 \%$ its nominal value takes place (SI, Fig. S7). The reason is that carbon felts, used for electrodes manufacturing, accumulate charge (like a capacitor) and quickly release it when the applied voltage is perturbated. The converter must limit this current overshoot by changing the voltage gradually in the stack. Moreover, the response time of the converter should be set based on the dynamic response of the stack. For these reasons, a mathematical model could be helpful in the converter design.

Fig. S8 (SI) shows the evolution of current density when applying different incremental voltages to the prototype. It appears that EMGBES stack has a nonlinear behavior. Artificial intelligence methods such as genetic programming and artificial neural network could be used for its modeling [48], but this approach is not straightforward. In Ref. [34], Muñoz et al. used a 8th order differential equation to model a EMG-BES system composed by a single cell (one pair of electrodes). A similar modelling approach was followed in this case, for the stack of 45 parallel EMG-BES cells. For electric grid integration of an EMG-BES plant, mechanistic details of electromethanogenic process are not essential, and a simple and practical model can fulfill the scope. Four models were tested (Eqs. (6)-(9)). Analyzing models results, it resulted that 1st and 2 nd order models could adequately fit experimental data, around $70 \%$ in steady and transient state (see Fig. 9 and SI, Fig. S9).

Higher order models could not represent well the EMG-BES stack in steady state (SI, Figs. S10 and S11). Therefore, the 1st order model represents the best choice for a future design of the electric converter, being it simple and quite accurate.

\section{Conclusions}

The study was focused on the characterization of an EMG-BES prototype for biomethane production and energy storage. The prototype was effectively inoculated in 68 days, applying a voltage of $0.7 \mathrm{~V}$ and a temperature of $32{ }^{\circ} \mathrm{C}$. Continuous feeding operation resulted in a current density of $0.5 \mathrm{~A} \mathrm{~m}^{-2}$ and $\mathrm{CH}_{4}$ production rates up to $4.4 \mathrm{~L} \mathrm{~m}^{-2} \mathrm{~d}^{-1}$. The competitive colonization of prototype by acetoclastic methanogenic microbes was observed. This aspect, although reducing its energy storage capacity, suggested that EMG-BES process could be retrofitted in traditional anaerobic digesters, with advantages in terms of biologic process stability and high-quality biogas production. A reduction of operation temperature from 32 to $25^{\circ} \mathrm{C}$ (relatively) favored the growth of electro-active bacteria, although causing an (absolute) decrease of both current density and $\mathrm{CH}_{4}$ production rate.

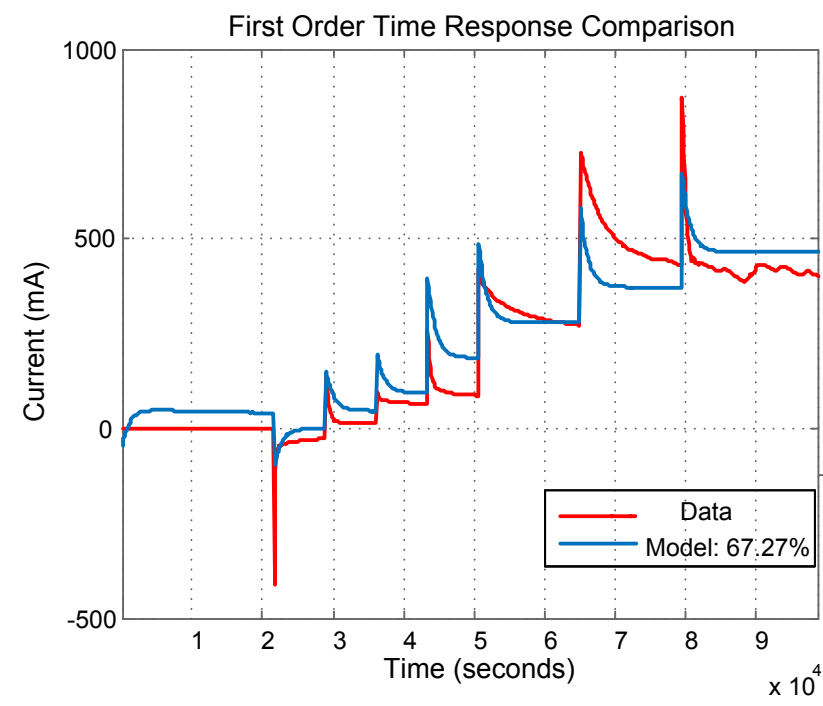

Fig. 9. EMG-BES modelling with 1st order system. 
The energy storage efficiency of pr ototype wa s es timated around 42-47\%, analyzing surplus $\mathrm{CH}_{4}$ production obtained when applying voltage to the EMG-BES stack. Resiliency to fluctuations of power supply was tested by imposing two periods in OCV (5-10 days duration), which caused a decrease of current density and (likely) affected microbial populations' activity, in terms of equilibrium between electro-active bacteria and acetoclastic methanogens. From the electrical point of view, a mathematical model was developed analyzing the experimental data coming from the I-V curve. The model will be useful to design the converter for EMG-BES plant connection to the electrical grid.

In the panorama of methanation technologies currently available for power-to-gas (chemical and biological methanation), the performances of this EMG-BES prototype are not yet competitive, especially in terms of specific $\mathrm{CH}_{4}$ production rate and energy storage density. On the other hand, the possibility to operate the plant at environment temperature and pressure is likely configuring a key advantage, in terms of energy storage efficiency. Fu ture re search on no vel el ectrode ma terials and architecture, among other themes, will likely lead to increased current (and power) density demand, which will lower capital costs and facilitate the scaling-up, resulting in a more favorable scenario for EMG-BES technology application to energy storage.

\section{Acknowledgements}

The authors wish to acknowledge Edxon Licon, David Gali, Ruben Rodriguez and the other Leitat collaborators who took part in the $\mathrm{P}$ ower2Biomethane project. Albert Guisasola is member of the GENOCOV research group (Grup de Recerca Consolidat de la Generalitat de Catalunya, 2017 SGR 1175, www.genocov.com).

\section{Funding}

This work has been financially supported by the Spanish Ministry of Economy and Competitiveness under the project Power2Biomethane (RTC-2016-5024-3, 2016). Moreover, the project has received funding from the European Union's Horizon 2020 research and innovation programme under the Marie Skłodowska-Curie grant agreement No 712949 (TECNIOspring P LUS) and from the Agency for Business Competitiveness of the Government of Catalonia.

\section{Conflicts of interest}

The authors declare no conflicts of interest. The funders had no role in the design of the study; in the collection, analyses, or interpretation of data; in the writing of the manuscript, or in the decision to publish the results.

\section{Appendix A. Supplementary material}

Supplementary data to this article can be found online at https:// doi.org/10.1016/j.apenergy.2019.114138.

\section{References}

[1] Fulli G, Masera M, Spisto A, Vitiello S. A change is coming: how regulation and innovation are reshaping the european union's electricity markets. IEEE Power Energ Mag 2019;17(1):53-66.

[2] International Renewable Energy Agency. Electricity Storage and Renewables: Costs and Markets To 2030, n.o October; 2017.

[3] Denholm P. Consequences of high-penetration renewables. In: Ginley DS, Cahen D, editors. Fundamentals of materials for energy and environmental sustainability. Cambridge: Cambridge University Press; 2011. p. 594-607.

[4] Notton G, Nivet ML, Voyant C, Paoli C, Darras C, Motte F, et al. Intermittent and stochastic character of renewable energy sources: Consequences, cost of intermittence and benefit of forecasting. Renew Sustain Energy Rev 2018;87:96-105.

[5] Denholm P, Ela E, Kirby B, Milligan M. Role of Energy Storage with Renewable Electricity Generation. Golden, CO (United States); Jan. 2010.

[6] DG ENER Working Paper - The future role and challenges of Energy Storage.
European Commission, Directorate-General for Energy.

[7] Blanco H, Faaij A. A review at the role of storage in energy systems with a focus on Power to Gas and long-term storage. Renew Sustain Energy Rev 2018;81:1049-86.

[8] Lewandowska-Bernat A, Desideri U. Opportunities of power-to-gas technology in different energy systems architectures. Appl Energy 2018;228:57-67.

[9] European Commission, Natural gas and biomethane for use in transport and biomethane for injection in the natural gas network; 2016.

[10] Bailera M, Lisbona P, Romeo LM, Espatolero S. Power to Gas projects review: lab, pilot and demo plants for storing renewable energy and CO2. Renew Sustain Energy Rev 2017;69:292-312.

[11] Zeng Q, Fang J, Li J, Chen Z. Steady-state analysis of the integrated natural gas and electric power system with bi-directional energy conversion. Appl Energy 2016;184:1483-92.

[12] Götz M, Koch AM, Graf F. State of the art and perspectives of CO2 methanation process concepts for power-to-gas applications. In: International gas union research conference; 2014

[13] Walspurger S, Elzinga GD, Dijkstra JW, Sarić M, Haije WG. Sorption enhanced methanation for substitute natural gas production: experimental results and thermodynamic considerations. Chem Eng J 2014;242:379-86.

[14] Otten R. The first industrial PtG plant - Audi e-gas as driver for the energy turnaround. In: CEDEC Gas Day 2014, Verona; 2014.

[15] DIN EN 16723-1 - Natural gas and biomethane for use in transport and biomethane for injection in the natural gas network - Part 1: Specifications for biomethane for injection in the natural gas network; 2017.

[16] DIN EN 16723-2 - Natural gas and biomethane for use in transport and biomethane for injection in the natural gas network - Part 2: Automotive fuels specification; 2017.

[17] Geppert F, Liu D, van Eerten-Jansen M, Weidner E, Buisman C, ter Heijne A. Bioelectrochemical power-to-gas: state of the art and future perspectives. Trends Biotechnol 2016;34(11):879-94.

[18] Heidrich T, Heller T. BioPower2Gas in Germany - Development, simulation and evaluation of optimal performance-adjustable biogas technologies. IEA Bioenergy 2018.

[19] Gorre J, Ortloff F, van Leeuwen C. Production costs for synthetic methane in 2030 and 2050 of an optimized Power-to-Gas plant with intermediate hydrogen storage. Appl Energy 2019;253:113594.

[20] Harnisch F, Aulenta F, Schröder U. Microbial fuel cells and bioelectrochemica systems. In: Comprehensive biotechnology, 2nd ed., vol. 1. Elsevier; 2011, p. 643-59.

[21] Butti SK, Velvizhi G, Sulonen MLK, Haavisto JM, Oguz Koroglu E, Yusuf Cetinkaya A, et al. Microbial electrochemical technologies with the perspective of harnessing bioenergy: Maneuvering towards upscaling. Renewable SustainableEnergy Rev 2016;53:462-76.

[22] Cheng S, Xing D, Call DF, Logan BE. Direct biological conversion of electrical current into methane by electromethanogenesis. Environ Sci Technol 2009;43(10):3953-8.

[23] van Eerten-Jansen MCAA, Jansen NC, Plugge CM, de Wilde V, Buisman CJN, ter Heijne A. Analysis of the mechanisms of bioelectrochemical methane production by mixed cultures. J Chem Technol Biotechnol 2015;90(5):963-70.

[24] Prajapati KB, Singh R. Enhancement of biogas production in bio-electrochemical digester from agricultural waste mixed with wastewater. Renewable Energy 2020;146:460-8.

[25] Zakaria BS, Ranjan Dhar B. Progress towards catalyzing electro-methanogenesis in anaerobic digestion process: fundamentals, process optimization, design and scaleup considerations. Bioresour Technol 2019.

[26] De Vrieze J, Arends JBA, Verbeeck K, Gildemyn S, Rabaey K. Interfacing anaerobic digestion with (bio)electrochemical systems: Potentials and challenges. Water Res 2018; 146:244-55.

[27] Sangeetha T, Guo Z, Liu W, Gao L, Wang L, Cui M, et al. Energy recovery evaluation in an up flow microbial electrolysis coupled anaerobic digestion (ME-AD) reactor: role of electrode positions and hydraulic retention times. Appl Energy 2017; 206:1214-24.

[28] Choi K-S, Kondaveeti S, Min B. Bioelectrochemical methane (CH4) production in anaerobic digestion at different supplemental voltages. Bioresour Technol 2017;245:826-32.

[29] Park J-G, Lee B, Park H, Jun H. Long-term evaluation of methane production in a bio-electrochemical anaerobic digestion reactor according to the organic loading rate. Bioresour Technol 2018.

[30] Yu J, Kim S, Kwon O-S. Effect of applied voltage and temperature on methane production and microbial community in microbial electrochemical anaerobic digestion systems treating swine manure. J Ind Microbiol Biotechnol 2019.

[31] Escapa A, San-Martín MI, Mateos R, Morán A. Scaling-up of membraneless microbial electrolysis cells (MECs) for domestic wastewater treatment: Bottlenecks and limitations. Bioresour Technol 2015;180:72-8.

[32] Guo H, Kim Y. Stacked multi-electrode design of microbial electrolysis cells for rapid and low-sludge treatment of municipal wastewater. Biotechnol Biofuels 2019;12(1):23.

[33] Heidrich ES, Dolfing J, Scott K, Edwards SR, Jones C, Curtis TP. Production of hydrogen from domestic wastewater in a pilot-scale microbial electrolysis cell. Appl Microbiol Biotechnol 2013;97(15):6979-89.

[34] Muñoz-Aguilar R, Molognoni D, Bosch-Jimenez P, Borràs E, Della Pirriera M, Luna Á. Design, operation, modeling and grid integration of power-to-gas bioelec trochemical systems. Energies 2018;11(8):1947.

[35] Coronado J, Perrier M, Tartakovsky B. Pulse-width modulated external resistance increases the microbial fuel cell power output. Bioresour Technol 2013;147:65-70.

[36] Coronado J, Tartakovsky B, Perrier M. On-line monitoring of microbial fuel cells 
operated with pulse-width modulated electrical load. J Process Control 2015;35:59-64.

[37] Tartakovsky B, Mehta P, Santoyo G, Guiot SR. Maximizing hydrogen production in a microbial electrolysis cell by real-time optimization of applied voltage. Int $J$ Hydrogen Energy 2011;36(17):10557-64.

[38] Hussain SA, Perrier M, Tartakovsky B. Real-time monitoring of a microbial electrolysis cell using an electrical equivalent circuit model. Bioprocess Biosyst Eng 2018;41(4):543-53.

[39] Hussain SA. Dynamic modeling and intermittent operation of a flow-through microbial electrolysis cell; 2018.

[40] Rodríguez-Alegre R, Ceballos-Escalera A, Molognoni D, Bosch-Jimenez P, Galí D, Licon E, Della Pirriera M, Garcia-Montaño J, Borràs E. Integration of membrane contactors and bioelectrochemical systems for $\mathrm{CO} 2$ conversion to $\mathrm{CH} 4$. Energies 2019;12(3):361.

[41] APHA. Standard methods for the examination of water and wastewater, 19th ed. Washington DC, USA: American Public Healt Association; 2005.

[42] Brown RK, Harnisch F, Wirth S, Wahlandt H, Dockhorn T, Dichtl N, et al. Evaluating the effects of scaling up on the performance of bioelectrochemical systems using a technical scale microbial electrolysis cell. Bioresour Technol 2014;163:206-13.

[43] Erable B, Féron D, Bergel A. Microbial catalysis of the oxygen reduction reaction for microbial fuel cells: a review. ChemSusChem 2012;5(6):975-87.

[44] Ruiz Y, Ribot-Llobet E, Baeza JA, Guisasola A. Conditions for high resistance to starvation periods in bioelectrochemical systems. Bioelectrochemistry 2015;106:328-34.

[45] Martin E, Savadogo O, Guiot SR, Tartakovsky B. The influence of operational conditions on the performance of a microbial fuel cell seeded with mesophilic anaerobic sludge. Biochem Eng J 2010;51(3):132-9.

[46] Measuring Small-scale Biogas Capacity and Production. Abu Dhabi: International
Renewable Energy Agency (IRENA); 2016.

[47] Rozendal RA, Hamelers HVM, Rabaey K, Keller J, Buisman CJN. Towards practical implementation of bioelectrochemical wastewater treatment. Trends Biotechnol 2008;26(8):450-9.

[48] Sewsynker Y, Gueguim Kana EB, Lateef A. Modelling of biohydrogen generation in microbial electrolysis cells (MECs) using a committee of artificial neural networks (ANNs). Biotechnol Biotechnol Equip 2015;29(6):1208-15.

\section{Glossary}

Acronym: Description

$B E S$ : Bioelectrochemical system

CE: Coulombic efficiency

COD: Chemical oxygen demand

EMG: Electromethanogenesis

EPS: Extracellular polymeric substance

HRT: Hydraulic residence time

MEC: Microbial electrolysis cell

$O C V$ : Open circuit voltage

$O L R$ : Organic loading rate

$P \& I D$ : Process \& instrumentation diagram

P2G: Power-to-gas

RES: Renewable energy share

SEM: Scanning electron microscopy

SNG: Synthetic natural gas

WWTP: Wastewater treatment plant 